\title{
Facebook as a Digital Public Sphere: Processes of Coloni- zation and Emancipation
}

\section{Bjarki Valtysson}

\author{
DCMC (Design-Culture-Mobility-Communication) Research Group, IT University of Copenhagen, \\ Copenhagen, Denmark, bjva@itu.dk
}

\begin{abstract}
In this article, Facebook, as a communicative space, is treated as a public sphere in order to identify processes of colonization and emancipation. The analysis focuses on Facebook's communicative-structural contexts, in particular from the viewpoint of user terms, user manoeuvre, privacy/data use policy, and ownership and use of uploaded material. The analysis is also based on qualitative data from Danish Facebook users, where the focus was on the users' motivation and use, their perceptions of ownership and consumerism, as well as their views on the public/private distinction that Facebook allows for/commands for. Theoretically, the article is grounded in Jürgen Habermas' various writings on the public sphere, as well as 'digital adaptations' to his theory. When looked upon from the communicative-structural contexts, processes of colonization are apparent, particularly in the various grey zones identified in Facebook's privacy/data use policy, its statements of rights and responsibilities and in the fashion in which users are treated as consumers. Even though the Danish Facebook users identified with this, they still conceive of Facebook as being an emancipative communicative space, as they prioritize different features of Facebook, namely networking, practical organisation, maintaining friendships, and leisure.
\end{abstract}

Keywords: Facebook, Digital Public Spheres, Networked Publics, Colonization, Emancipation

\section{Introduction}

Facebook is one of the most influential media platforms of our times. It is not just so because of the current 800 million active users (Facebook, n.d., d), but also when taken into consideration the time users spend on generating this specific media environment - and thereby the impact it has on the daily life of its active users and the way that society is framed and represented at this given point in time. As every media environment, Facebook is a restricted environment that institutionalizes specific discourses that have certain things in common. This is the case with every technology - as technologies are essentially political (Winner, 1986), inviting certain uses and concordantly affecting societal structures with their inherent affordances. From the context of this article, Facebook is looked upon as public sphere(s), which - like all public spheres - is tailored in a certain way thereby inviting the publics generating communication within its sphere(s) certain forms for interaction and participation. As more people are choosing this particular media environment, investing time and effort into affecting and being affected by its streams of information, it is of much importance to analyse further the conditions set for the communication, as well as the actual use and perceptions of its users. Originally, Facebook constituted a micro public sphere - but as more users invest time and efforts within this particular media environment, it has for some time now reached up to macro structures of society thereby affecting general behavioural patterns of citizens.

This is certainly the case in Denmark, where $54 \%{ }^{1}$ of the population uses social media, Facebook leading the flock by far. Therefore, Facebook proves to be an interesting example of a communicative space, where much interaction between users take place, and hence, the aim of this article is to analyse elements of Facebook constituting a digital public sphere from the viewpoint of content creation generated by Danish Facebook users.

The public sphere has been conceptualised as a communicative space that resides between and mediates the different interests of the system (market and state) and the lifeworld. In critical theory as evolved by the Frankfurt School, and particularly by Jürgen Habermas (1987; 1989; $1992 ; 1996 ; 1999 ; 2006)$, the system is perceived as colonising the lifeworld. Seen from this perspective the financial prowess of the market and the administrative power of the state act instru-

\footnotetext{
${ }^{1}$ These numbers are extracted from Statistics Denmark. These statistics show that $97 \%$ of young female (16-24) and $87 \%$ of young males (16-24) use social media (Nyt fra Danmarks Statistik). Facebook is the most used of social media sites with average of 71 million visits each month in 2010, mounting up to 22 million hours on 1.7 billion Facebook pages (Danskernes brug af internettet 2011).
} 
mentally and smother the communicative actions taking place in the lifeworld. Hence, the public sphere has seized to be an inclusive communicative space for rational-critical debate, and is now a venue for the instrumental rationale of the system.

From the perspective of people engaged with user-generated content on Facebook, issues on privacy, surveillance and the economic gains of Facebook can be seen as processes of colonization. However, the processes generated by the users on Facebook also have potentials of emancipation, for instance in terms of cultural capital, networking, exposure, political empowerment, etc. The aim of this article is to analyse Facebook as a digital public sphere and identify processes of colonization and emancipation within this specific communicative space. This will be conducted by analysing Facebook as a media environment from a communicative-structural context (user terms, user manoeuvre, privacy policy, and ownership and use of uploaded material) and by collecting qualitative data from Danish Facebook users.

I will start by accounting in general terms for the theoretical framework, methodology and what kind of data analysis is conducted. The subsequent section focuses on defining further how this article conceptualises the notion of digital public spheres - which then will be put to use in the section Facebook: The Colonizing Side - which concentrates on the communicative-structural analysis. Then a section called Facebook: The Emancipative Side follows, where the focus is on an analysis of the qualitative data collected from my interviewees. Finally, this article ends with putting the different processes of colonization and emancipation in a broader perspective, and situating Facebook within that perspective.

\section{Theory, Methods and Data Analysis}

As the main purpose of this article is to detect processes of colonization and emancipation within Facebook as a public sphere, Jürgen Habermas' various writings and rewritings on the public sphere will serve as theoretical foundations. This theoretical framework will be used both in framing the communicative-structural analysis of Facebook as a media environment, as well as guiding the coding of the qualitative interviews conducted with Danish Facebook users.

In all, seven in-depth semi-structured qualitative interviews were conducted (Gaskell 2000; Creswell 2009; Kvale and Brinkmann 2008) with four women and three men. The age group chosen was 20-25 years. As Danish statistics on use of social media prove (Nyt fra Danmarks statistik 2011) young people from 16-24 are the ones that interact mostly with social media, which makes them likely to be aware of the different functions, and user manoeuvre, that Facebook as a media environment allows for. The interviewees accounted for a more responsible Facebook use in their current age that differ from the "irresponsible early days" of their Facebook use, which explains why I decided not to interview users under the age of twenty. It was my presumption that this assumed "maturity" in the interaction of the interviewees and Facebook allowed them to contextualise the different forms their interactions take, for instance why they use the medium?; what motivates their use?; what the main purposes are?; their views on privacy policy and terms of conditions; intersections between the public realm and the private one; along with questions regarding marketing and consumerism.

Following the interviews, the seven interviewees logged on their Facebook profiles and allowed me to video record their routine use of Facebook, while verbalising the purpose of each operation made. This allowed me to compare the data from the interviews, with that of the observations conducted on their use of Facebook, providing me with additional information - especially regarding purposed use (verbalised) and actual use (the interactions taken on Facebook).

Most of the interviews were conducted in July and August 2011. However, as Facebook made recent changes on the interface and privacy policy, I conducted an interview in October 2011 as well to capture the affects of these changes. Additionally, I corresponded with the interviewees from July and August, regarding the effects of recent changes. This updated follow-up is included in the forthcoming analysis.

The interviewees were chosen using a snowball sampling technique. All interviews were conducted in Danish, and recorded and transcribed. The analysis of the interview transcripts is based on the multidimensional character of the interviewees signifying processes (Schrøder 2000; Schrøder et al. 2003), looking particularly at the interviewees' motivation and use; their perceptions on ownership and consumerism; as well as their views on the public/private distinction that Facebook allows for/commands for. The relevant references from each interview were joined and summarized in order to extract significant information from each of these topics - and quotes were translated from Danish to English. Finally, I changed the names of my respondents to ensure confidentiality. I only refer to them with altered initials. 


\section{Digital Public Sphere(s)}

An obvious point of departure for this article is to define further what I mean by digital public sphere(s) and user-participation - and I will go through some lengths to define these and anchor to the digital environment in question. However, it seems valid to ask why this is at all an interesting subject to investigate? - Why Facebook? - And why the public sphere? I have already hinted at the answer in the introduction, but the most direct answer has to do with volume, expected use and actual use of the medium, quality and terms of participation. With its worldwide number of 800 million users, Facebook is a digital environment that constitutes a communicative arena which colossal amount of people takes advantage of each day. But just like the original blueprint of Habermas' public sphere, Facebook is a pre-programmed environment that allows for certain interactions, encouraging certain behaviours, communicative acts, and users - thereby excluding certain users, certain semiotic expressions, and communicative acts. In short, Facebook is not an inclusive communicative space, but on the contrary, an exclusive one.

Furthermore, this space pushes certain agendas - and like all spaces, it is saturated with power. But this has always been the case with the notion of the public sphere.

In its most direct form, the public sphere is a space, or an environment, which facilitates communicative acts between citizens. In the original blueprint, Habermas differentiates between the public sphere in the world of letters (later conceptualised as the cultural public sphere) and the political public sphere, emphasising the former's role in serving as an apolitical venue for citizens to discuss and deliberate matters of common concern. In its ideal manifestation, these would be venues where societal status - social, cultural and economic capital - would be disregarded and where everyone would be able to participate $(1989,36-37)$. The participation of the public is central to this ideal deliberation and the "environments" that Habermas privileged in the original blueprint were the British coffee houses, the French salons and the German table societies, and later newspapers, journals and public assemblies where cultural-social-political discussions took place. When analysing Facebook as a public sphere, the publics presented there will have to be included, as the public sphere is merely "conditions of communication under which there can come into being a discursive formation of opinion and will" (Habermas 1992, 446). However, it is the communicative public that generates these discursive formations. These two - the public(s) and public sphere(s) are interrelated. The former is an environment, the latter acts on and within that environment. This is in line with Splichal's observations as he maintains that "[a] public sphere cannot act, it cannot communicate, but a/the public can" $(2010,28)$. Here, Facebook can be considered a public sphere and users generating the communication that takes place on Facebook, can be considered as publics. Again, it is vital to underline Habermas' distinction between critical debate in the world of letters and rational-critical debate in the political realm. Indeed, as privatized individuals, the bourgeois had the ambivalent position of being both bourgeois and homme; and this ambivalence transmitted from the private spheres to the public sphere: "This ambivalence of the private sphere was also a feature of the public sphere, depending on whether privatized individuals in their capacity as human beings communicated through critical debate in the world of letters, about experiences of their subjectivity or whether private people in their capacity as owners of commodities communicated through rational-critical debate in the political realm, concerning the regulation of their private sphere" (Habermas 1989, 55-56). Furthermore, it is important to state that like any other public sphere, Facebook is a fluid, ever-changing environment, which affects the types of publics, and the agency of different kinds of publics that choose to communicative within its sphere. This fluidness is clearly manifested in the long chain of changes in Facebook's privacy policy, user terms, and of course in the media environment as such. Recent changes in both the interface and privacy policy of Facebook (now referred to as data use policy), such as easier customisation in choosing specific audience for status updates, the news ticker, updates to the news feed (recent stories and top stories), tag locations in posts, and the timeline, act as clear indicators of such 'fluidity'.

In the latter part of his seminal work on the structural transformation of the public sphere, Habermas detects degeneration; a process which he terms feudalization of the public sphere, mainly caused by the commercialization and a resulting depolitization of the media, and here he echoes some of the concerns of Adorno (2001) and Horkheimer (2002), in particular when it comes to their negative account of the culture industries and the mass media. Here, Habermas gets entangled in a paradox, as increased participation apparently leads to less quality: "Reason, which through public use of the rational faculty was to be realized in the rational communication of a public consisting of cultivated human beings, itself needed to be protected from becoming public because it was a threat to any and all relations of domination" (35). The consequence of mass-mediated culture of consumption is the loss of citizens' dual role as bourgeois and homme, and therefore the "public sphere in the world of letters was replaced by the pseudo-public or sham-private world of culture 
consumption" (160). The mass mediated public sphere lost its political character and psychological facilitation was prevented because of commercial consumer attitude.

For Habermas, participation is a keyword - here associated with serious involvement and consumption: "Serious involvement with culture produces facility, while the consumption of mass culture leaves no lasting trace; it affords a kind of experience which is not cumulative but regressive" (166). When these thoughts are translated to people's use of Facebook, it is a valid claim to question what kind of user-involvement Facebook facilitates, and indeed, whether such processes are described as being colonising or emancipative. In his original work, Habermas reaches the conclusion that private enterprises and the state do not treat people as citizens, but as consumers, and that the instrumental rationality of money and power colonise rational-critical deliberation - a claim that keeps resurfacing in his later works. Habermas detects a strategic colonisation by the economic and bureaucratic means of the market and the state towards the lifeworld - and this gives rise to structural violence exercised by systemic restriction of communication: "In the end, systemic mechanisms suppress forms of social integration even in those areas where a consensus-dependent coordination of action cannot be replaced, that is, where the symbolic reproduction of the lifeworld is at stake. In these areas, the mediatization of the lifeworld assumes the form of a colonization" (1987, 196; italics in the original).

Excessive colonization results in structurally generated loss of meaning and freedom, caused particularly by media steered sub-systems. The question is whether Facebook represents such sub-system, or whether it contains emancipative counter potentials generated from the lifeworld, in particular from the viewpoint of cultural reproduction, social integration and socialisation? These kind of emancipative counter potentials are generated from communicatively structured domains that do not respond to the medium of money and power - and here Habermas places amongst other things human rights, individual self-realisation, women movements, and autonomy movements working in favour of regional, linguistic, cultural and religious independence - and from the perspectives of this article, cultural participation $(1987,393)$.

Habermas' public sphere has been criticised from various angles. These include too much faith in the power of discursive argumentation and rational-critical communication, the illusion of its inclusiveness, its homogeneity, its absence of passion and the irrational, its lack of accounting for pluralistic publics, its denial of the meaning and importance of financial, symbolic and cultural capitals, its generalisations concerning the evils of the state and the market, and its homogenous view on mass media (see for instance Calhoun, 1992; Curran, 2002; Dahlberg, 2005; Dahlgren, 2009; Fraser, 1992, 2007; Garnham, 1990; Kellner, 1990; Keane, 2000; McGuigan, 2005; Mouffe, 2000 and 2005; Negt and Kluge, 1993, Valtysson, 2010).

However, as too often forgotten, Habermas' more recent adaptations $(1996,1999,2006)$ do account for a more versatile view as the metaphor of the network is now prevalent in his conceptualisation of the public sphere which he describes as "a highly complex network that branches out into a multitude of overlapping international, national, regional, local, and subcultural arenas" (1996, 373). Furthermore, these public spheres are differentiated into levels depending on the density of communication, organizational complexity and range - from episodic publics, through occasional or arranged publics, "up to the abstract public sphere of isolated readers, listeners, and viewers scattered across large geographic areas, or even around the globe, and brought together only through the mass media" (1996, 374; italics in the original). This conceptualisation of public spheres and publics is more in line with Fraser's post-bourgeois hybrids, with their weak, strong, intra and interrelations $(1992,2007)$ and Keane's emphasis on a networked construction of micro, meso and macro public spheres (2000).

The mass media is and has always been central to Habermas' writings on the public sphere and even though he does not directly address the "digital add-on", he is attentive towards the need of self-regulating media systems and the importance of audience response: "Mediated political communication in the public sphere can facilitate deliberative legitimation processes in complex societies only if a self-regulating media system gains independence from its social environments, and if anonymous audiences grant feedback between an informed elite discourse and a responsive civil society" $(2006,411-412)$. From its very start, there has been certain euphoria over the democratic potentials of the Internet, a process that has escalated with terms such as the social web, web 2.0 and social network sites - which despite their fuzziness do imply increased potentials of user involvement and user-generated content. These processes do without doubt expand the potentials of individual opinion into public opinion, the achievability of participation and the development of a transnational, deterritorialized public sphere, consisting of the global communication networks of individuals, organizations and movements (Splichal, 2010). 
However, despite the empowering, emancipative potentials of the various social network sites, it is still media power on a macro scale that designs the media environments for the best known and widely used web 2.0 platforms. From a system perspective, as Habermas understands it, mass media and processes of mass communication still generate streams of macro-power. One has only to think of the large multi-media corporations and Internet companies (Time Warner, Disney, News Corp., Bertelsmann, NBC, CBS, Viacom, Google, Microsoft, Yahoo! and Apple), and their different media holdings and ownership relations (McChesney, 1999; Arsenault and Castells, 2008) to get another more colonizing view of the emancipative promises of the Internet, and the current media landscape. Nevertheless, many of the media environments often associated with web 2.0 (despite ownerships and issues related to surveillance and privacy) do encourage user involvement where networked publics (Ito, 2008) communicate through digital public spheres. As a result of digitalisation processes, media are by now essentially digital, which means that "the mediated public sphere is by now a digital public sphere" (Gripsrud and Moe 2010, 9).

But despite an observation of this sort, Habermas' insights still apply as principally "analogue" and "digital" public spheres cannot but coexist in this culture of real-virtuality (Castells, 2000), where processes of convergence affect technologies, spaces and practices (Papacharissi, 2010) alike. This is evident when looked upon from the viewpoint of media power, which remains to be essential for Habermas' theorisation of the public sphere: "The public sphere, simultaneously prestructured and dominated by the mass media, developed into an arena infiltrated by power in which, by means of topic selection and topic contributions, a battle is fought not only over influence but over the control of communication flows that affect behaviour while their strategic intentions are kept hidden as much as possible" $(1992,437)$. As the data from the qualitative interviews shows, the strategic intentions of Facebook seem to be successfully hidden, as the respondents do not generally perceive Facebook to be a narrowly structured, steering medium - but on the contrary, a medium that facilitates user-generated content, emancipation and participation.

\section{Facebook: The Colonizing Side}

When Facebook is looked upon from the viewpoint of digital public spheres generated by the user-generated content of networked publics - several issues seem to be of importance, of which some point towards processes of colonization and other towards emancipation. To grasp the various features of Facebook, I will start with accounting for the medium's communicative-structural context, mainly focusing on its user terms, user manoeuvre, privacy policy, and ownership and use of uploaded material. I will then account for the data extracted from the qualitative interviews and the observation conducted on Danish users on Facebook.

Facebook is a multi-semiotic media environment where users communicate with text, links, photos, videos, and sound - using different features such as chat, messages, status updates, and the wall. In addition, users can participate in networks, groups and 'like' pages, confirm or decline participation in upcoming events, accept game and app requests, 'check in' in places, account for their geographical location, write notes, tag photos (both their friends but also brands, products and companies), post classified ads on the Marketplace, purchase and use Facebook Credits to buy gifts and virtual goods (currently only for games), watch Facebook Live, receive sponsored stories and sponsored ads - and now, construct their own timeline. This is not an exhaustive enumeration of the functions inherent in Facebook, but points towards important features that touch upon processes of emancipation, as well as colonization.

From the viewpoint of digital public spheres, the news feed is of particular importance as this is the venue where users share their status, photos, links, and videos (along with a function called questions). Prior to the recent changes, users could choose whether to include everyone, friends of friends, friends only, or customise. After the changes, what used to be labelled as everyone, is now called public - and the process of tailoring different publics has been made more transparent. This is very much in line with the networked adaptation, which Habermas later incorporated within his conceptualisation of the public sphere, depending on the density of communication, range and organizational complexity. However, this is not an inclusive sphere and certainly not a sphere that disregards status altogether - but as already discussed, this has never been the case with the public sphere. In this case users accept friends and add friends, creating a network, which can be expanded or shrunk, depending on account settings.

When the user manoeuvre is further scrutinized, users were for a long time only allowed to write 500 characters in their status updates. If the update exceeded the limit, users were encouraged to edit the update and post it as a Note instead. After recent changes in September 2011, the amount of characters is set up to 5000 . However, this is still an inherent limitation in amount of text which is not at all in line with the rational-critical deliberation that Habermas envisages that takes place in 
the public sphere. This is an important fact that finds affinities in another popular social networking service - Twitter - which conditions its users to 140 characters for each tweet. These kinds of widespread "micro-blogging" operations are interesting from the viewpoint of the public sphere, as they indicate structural problems inherent in these media-environments. At the same time, Habermas does not privilege other semiotic expressions, such as photos, videos - and the distribution of links/information. Digital public spheres do however thrive within digital networks, which are both multimodal and multichannel, meaning they refer to various technologies of communication as well as to the organizational arrangements of the communication sources (Castells 2009, 130). This does however not change the fact that only allowing 500/5000 characters (and 140 characters in the case of Twitter) limits the potentials of users to engage in wide-ranging deliberation. Additionally, recent changes to the news feed indicate more control to Facebook in providing its users with information, as the news feed is now divided into recent stories and top stories. This means that Facebook decides which updates to prioritize and which not. On the actual criteria defining the selection process Facebook claims: "Your top stories are stories published since you last checked News Feed that we think you'll find interesting" (Facebook, n.d., e).

Regarding the public vs. private nature of Facebook as a media environment, users have several options at their hands when granting access to their updates, from sharing with everyone/public and down to selecting individuals from your network of friends. However, Facebook's privacy settings have been subject to debates as the default has always been, and still is, to share broadly (boyd and Hargittai, 2010). Facebook is privately owned and most of its revenues come from advertising, where the company works closely with investors like Microsoft. ${ }^{2}$ It is therefore in Facebook's direct interest that information is shared as much as possible; a fact that is obvious when looking at the recommended privacy settings. Prior to recent changes, Facebook recommended that status, photos and posts, bio and favourite quotations, family and relationships were open to everyone; photos and videos you are tagged in, religious and political views, and birthday were open to friends of friends; and permission to comment on your posts and places you check were with friends only. Only contact information were reserved for the miscellaneous othercategory. This is still the case. Indeed, after recent changes the main difference lies within terminology and in the transparency of the actual interface when users update their status.

This is not only interesting from the viewpoint of recommended privacy settings, but also from the viewpoint of how this particular media environment is designed. Why bio and favourite quotations? Why relationships? Why religious and political views? It is of course up to the individual users to fill these categories with content, but as my analysis of the Danish users demonstrates, they are not attentive towards this particular issue. My respondents did know of some polemics regarding privacy settings and Facebook - but did not make much of that as they felt they were in charge of their own profile. None of them had read Facebook's privacy policy (one had looked at parts of it), and they trusted Facebook.

However, when tracing Facebook's record in introducing new services and changing terms of conditions and privacy settings, these actions never fail to cause polemics (boyd and Hargittai, 2010). Reaching from privacy settings, to child safety, to the inability to terminate accounts, to services like Beacon (includes third-party websites), to data mining, to photo recognition - Facebook has had an unfortunate record of the 'shoot first, ask later' rhetoric.

On Facebook's 'old' privacy policy (revised 22 December 2010) it is maintained that one of the main incentives for joining the platform is to share content: "One of the primary reasons people use Facebook is to share content with others" (Facebook, n.d. b) - and just as with the content (metadata), the transactional information (payment source account number) and friend information - these information are automatically stored. However, users are directed to the payments page and to the help page to get advice on how to remove this data. Regarding information that Facebook collects when users interact with the platform, some degrees of site activity information, access device, browser information and cookie information are stored: "We keep track of some of the actions you take on Facebook, such as adding connections (including joining a group or adding a friend), creating a photo album, sending a gift, poking another user, indicating you 'like' a post, attending an event, or connecting with an application" (Facebook, n.d., b). The same goes for collecting information "about your browser type, location, and IP address, as well as the pages you visit" (Facebook, n.d., b) and cookies that 'make Facebook easier to use, to make our advertising better, and to protect both you and Facebook' (Facebook, n.d., b).

\footnotetext{
${ }^{2}$ October 24, 2007, Facebook and Mircrosoft Corp. announced that they would expand their advertising partnership and that Microsoft will take a $\$ 240$ million equity stake in Facebook's next round of financing at a $\$ 15$ billion valuation (Microsoft ${ }^{\circledR}$ News Center, n.d.)
} 
In the section on information Facebook receives from third parties, it is made known that each time users connect with a Platform application or website, Facebook will receive information from them, and this includes information about actions users take. It is also explicitly phrased that Facebook may institute programs with advertising partners and other websites - as the following quotation from the 'old' privacy policy demonstrates:

- "We may ask advertisers to tell us how our users responded to the ads we showed them (and for comparison purposes, how other users who didn't see the ads acted on their site). This data sharing, commonly known as "conversion tracking," helps us measure our advertising effectiveness and improve the quality of the advertisements you see".

- "We may receive information about whether or not you've seen or interacted with certain ads on other sites in order to measure the effectiveness of those ads" (Facebook, n.d., b).

Furthermore, Facebook also collects information about users from other Facebook users, "such as when a friend tags you in a photo, video, or place, provides friend details, or indicates a relationship with you" (Facebook, n.d., b).

When users mark their information as being viable to "everyone" as was recommended in Facebook's account settings prior to recent changes - this information could be accessed by everyone on the Internet (not only people logged on to Facebook) and can be imported, exported, distributed and redistributed by Facebook (and others) without privacy limitations. Additionally, Facebook "serves" personalized and social advertising to its users. On the former it says: "We allow advertisers to choose the characteristics of users who will see their advertisements and we may use any of the non-personally identifiable attributes we have collected (including information you may have decided not to show to other users, such as your birth year or other sensitive personal information or preferences) to select the appropriate audience for those advertisements" (Facebook, n.d., b). The very notion of "serving" advertisements and "to make advertisements more interesting and more tailored to you and your friends" (Facebook, n.d., b) is in concordance with the general tone in Facebook's privacy settings - i.e. they are meant to communicate the illusion that this is to protect and benefit the users, rather than Facebook Inc.

The same can be said about the clause on Facebook providing its users with services where it is maintained that these service providers are helping Facebook to bring us (the users) the services they offer. However, "[t]hese service providers may have access to your personal information for use for a limited time, but when this occurs we implement reasonable contractual and technical protections to limit their use of that information to helping us provide the service" (Facebook, n.d., b). No further account is given on what "reasonable contractual and technical protection" entails.

Finally, concerning the deletion and deactivation of accounts, Facebook's "old" policy offered tools to do that. The privacy policy emphasised that when users delete accounts on Facebook "it is permanently deleted from Facebook" (Facebook, n.d., b). However, it also says that "we may retain certain information to prevent identity theft and other misconduct even if deletion has been requested" (Facebook, n.d., b) - a statement that undermines the execution of the actual deletion of profiles.

Most of these issues have not fundamentally changed in recent adaption of Facebook's privacy policy (revised 23 September 2011) - which is now called data use policy. User's name, profile picture, networks, username, User ID are still public, and Facebook still exceeds vast extraction of data about its users from other "friends", games, applications and websites, which users interact with. Facebook keeps on registering users interactions such as searching for friends or specific pages, as well as metadata (time, date, and place) on photos and videos that users upload. As the following somewhat lengthy quotation from the new data use policy proves, the information Facebook collects about users is vast - and on some areas it is indeed more far fetching than in the older privacy policy:

- "We receive data from the computer, mobile phone or other device you use to access Facebook. This may include your IP address, location, the type of browser you use, or the pages you visit. For example, we may get your GPS location so we can tell you if any of your friends are nearby".

- "We receive data whenever you visit a game, application, or website that uses Facebook Platform or visit a site with a Facebook feature (such as a social plugin). This may include the date and time you visit the site; the web address, or URL, you're on; technical information abut the IP address, browser and the operating system you use; and, if you are logged in to Facebook, your User ID". 
- "Sometimes we get data from our advertising partners, customers and other third parties that helps us (or them) deliver ads, understand online activity, and generally make Facebook better. For example, an advertiser may tell us how you responded to an ad on Facebook or on another site in order to measure the effectiveness of - and improve the quality of - those ads" (Facebook, n.d., a).

As can be seen from the quote, registration of location data has indeed been expanded in the new data use policy. Furthermore, a new and upcoming feature in Facebook is the so-called Timeline, which is composed of cover, stories and apps. This feature is an attempt to a total mapping of users timeline/lifespan, where users are encouraged to provide stories and documentations from different periods in their lives, along with notifying other users, and Facebook Inc., about the apps in use. This makes the parts in the new data use policy, regarding what information users share with applications, particularly interesting.

In short, when users go to a game or an application, Facebook gives the application automatically the user's User ID, as well as a given user's friends-list. This feature is supposed to make the experience more social, as users can find friends using the application. In addition, the application automatically accesses the user's public information - and the same is the case when people you share with use applications. So, if users want to keep applications away from getting their information, the only way to do that is to drop that feature altogether: "If you want to completely block applications from getting your information, you will need to turn off all Platform applications. This means that you will no longer be able to use any games, applications or websites" (Facebook, n.d., a). As Facebook's Timeline-feature incorporates apps in its design, users are clearly encouraged to share through applications - which essentially means that users share more information to third party actors.

The new data use policy is more detailed in its description on what users actually share when they interact with Facebook, which corresponds with the changes in the interface of status updates - where the process of deciding upon whom to share with has been made more transparent. Even if this can be looked upon as dimensions of emancipation, other changes in the new data use policy lean towards further colonization. A feature called instant personalization allows Facebook's partner sites to "create a more personalized and social experience than a social plugin can offer" (Facebook, n.d., a). As the case is with applications, users are also free to turn off this feature - but this is all the same an attempt to gather even more information of users as consumers, which makes it an act of colonization. The advertising settings are similar in the data use policy as they were in the older policy, i.e. users are constantly targeted as consumers, and unlike the process with the new instant personalization feature and apps, users are not empowered to turn the advertising processes off.

When looked at from the viewpoint of colonization and emancipation, Facebook's older privacy policy and the new data use policy are of course tailored by Facebook Inc. to protect the user and to explain to people what it actually entails when they share, buy, and participate in this specific media environment. However, despite this reworking of the policy, which allows users to protect themselves more when compared with earlier versions of the privacy policy - there is still considerable registration of information taking place regarding activity, browsing, information flow between Facebook and other sites, and information collection through other Facebook users. Indeed, Facebook is moving towards increased data gathering from its users, as services like instant personalization and timeline is a continuation of the process of receiving/sharing information about its users to and from other websites. This information is used for commercial purposes, which makes it an act of colonization, as users are turned into consumers.

Furthermore, there are still various loopholes in Facebook's data use policy. This is for instance the case when deleting accounts and access of information by third parties. An eerie example of this is in memorializing accounts of deceased users where it is stated that "[w]e also may close an account if we receive a formal request from the person's next of kin" (Facebook, n.d., a). It is this "may" that is not reassuring. On the other hand, the new data use policy has made the process behind deleting accounts more transparent. This does, however, not change the fact that Facebook's data use policy contains grey zones where it is not at all clear to the user what is exactly stored and how Facebook intends to use the data. Recent changes to the news feed, the instant personalization and the timeline are case in point.

Another dimension that is important to the notion of digital public spheres is the concept of participation - and as Facebook is primarily about sharing information, questions concerning ownership of the participating activities on Facebook are of much importance. In Facebook's statement of rights and responsibilities it is stated that users own the content and information posted on Face- 
book. However, there is an addition: "For content that is covered by intellectual property rights, like photos and videos ("IP content"), you specifically give us the following permission, subject to your privacy and application settings: you grant us a non-exclusive, transferable, sub-licensable, royaltyfree, worldwide license to use any IP content that you post on or in connection with Facebook" (Facebook, n.d., c). Furthermore, when users publish using the "everyone" setting, "it means that you are allowing everyone, including people off of Facebook, to access and use that information" (Facebook, n.d., c). This is particularly interesting as the recommended setting for status, photos and posts is set on "everyone". This is still the case - but as previously mentioned "everyone" has been replaced with "public".

Again from the viewpoint of Habermas' public sphere, this is a clear act of colonization, as Facebook does no only claim rights to use the data provided by its users - but it is actually dependent on exploiting the information provided by its users for commercial purposes. To put it bluntly; Facebook Inc. provides the environment and sets conditions and rules; users fill it with content (i.e. do all the work) - while Facebook Inc. gets the profits. And that has to be considered an act of colonization.

This is of course in stark contrast to the emancipative promise of the 'participative web', usergenerated content - and the emancipative, empowering potentials in consumers/users turning producers. Therefore, terms such as prosumers (Toffler, 1980), produsers (Bruns, 2008), users-turned producers and the mass self-communication of the creative audience (Castells, 2009) that imply fundamental changes in the relationship and interaction between producers and consumers/users seem a bit hollow. In some sense, this has to do with too much belief in beneficial aspects of participation, where supposedly those involved automatically gain from it. In Carpentier's view, this view de-contextualizes participatory practices and disconnects them from democratic values such as empowerment and equality: "This de-contextualization leads also to the belief that the societal appreciation and impact of participatory practices will not be affected by the political-ideological, communicative-cultural and communicative-structural context" $(2011,22-23)$.

However, the participatory practices of Facebook users are certainly affected when looked upon from my communicative-structural analysis of user terms, user manoeuvre, privacy, and ownership and use of uploaded material. Here, the communicative structures of Facebook are designed to allow certain user behaviour, certain forms for participation, which from this point of view, is clearly more beneficial to Facebook, than for its users. Indeed, as Fuchs states in his account of ventures like Google, YouTube, MySpace and Facebook: "While no product is sold to the users, the users themselves are sold as a commodity to advertisers" $(2010,191)$. Fuchs goes as far as maintaining that the "category of the produsage/prosumer commodity does not signify a democratization of the media toward a participatory or democratic system, but the total commodification of human creativity" (2010, 192).

This kind of analysis certainly confirms Habermas' view on the colonising instrumentality inherent in the system, but is this really so one-dimensional? There is no doubt from my analysis that from a communicative-structural point of view, Facebook is a media environment saturated with macro-power that acts in a colonizing, instrumental manner, with the aim of becoming more powerful and exceeding more revenues. But isn't there also something in it for the user?

\section{Facebook: The Emancipative Side}

From the viewpoint of Habermas' theory on the public sphere the processes of colonization already identified within Facebook as a media environment point specifically towards the grey zones in the privacy policy and the data use policy as well as in the ways Facebook utilizes its vast collection of user data to target users as consumers. Despite of this, the seven Facebook users all emphasised that they rather see Facebook as being an emancipative media environment, rather than colonizing. It is important to note, however, that they were all to a certain degree conscious of the colonization processes already identified. They just did not weigh these processes as being as important as the emancipative ones. Furthermore, the respondents all maintained they were in charge of this media environment, i.e. they used it according to their preferences, rather than on what they perceive to be the terms that Facebook builds around the environment. In the following analysis I look specifically at the motivation and use (their perception of themselves as users), their views on advertising and ownership of uploaded material, as well as how Facebook affects their perceptions of public and private. 


\subsection{Motivation and Use}

As previously noted, all of the respondents perceive themselves as in "charge" of Facebook as a media environment, and all of them have certain agenda in their communication on Facebook. All of them mention communication as being the prime reason for being on Facebook, particularly maintaining friendships (none of them mention acquiring friendships), organising practical matters, networking, and to look at pictures: "Facebook has become so wide-ranging. You can find everything there. I use it to contact my friends; to organize us and agree were to meet. But I also use it if I am going to a concert, or to see if anything is happening - then you can just go in there and see what is happening. So I use it to orient myself within my immediate environment. And I do look at many pictures" (JP). All of the respondents underline Facebook's importance regarding pictures, especially in association with travels, both to show others where they are/have been, but also to withhold relations acquired while travelling: "I upload pictures, especially while travelling, so my friends can follow me and see what I am up to. I probably use Facebook the most while I am travelling. I use more time on it as it is a more practical way to share than writing e-mails to everyone" (GI). This also points towards a general trend identified amongst the interviewees - Facebook is increasingly chosen as the most convenient platform for practical organisation. Instead of sending e-mails or text messages on the mobile phone, the primary medium for these tasks is now Facebook.

An important empowering dimension of the respondents' use of Facebook is that they all tailor it according to their own needs. The student says "that much of my use is related to my studies and the organisation of study groups" (SU). The entrepreneur says: "I do not write status updates unless it has something to do with my company" (BT). And the one working in TV production admitted: "to be a bit addicted as I am by nature a curious person that wants to know what is going on with the people that I know. On the other hand, it is beneficial to know people in my line of work" (JU) pointing towards the importance of Facebook in withholding professional networks. One recurring answer as to why use Facebook is recognition. When users upload photos, distribute links or write a status update, they expect something in return - which is why they "like" similar things with other friends.

All of the interviewees do, however, detect certain ambivalence in their use calling it "a waste of time" (BT), "a way of spending time" (LO) (in particular with access through mobile phones), pointing towards routine daily activities, which Facebook has become an in-dismissible part of. Furthermore, they all reflect back on going from irresponsible and naïve use, to a more responsible and mature use. By doing this, they indicate a certain learning process in order to "tame" Facebook as a media environment, and take control over it: "I think that Facebook is very positive if you can figure out how to use it. You need to take some precautions, as there are many traps to fall in. It is more difficult to be private than to be public, as you need to actively change the settings and make them more private. I do not think this is a considerate system" (LO).

More respondents indicate similar transition from the early "open" days to a more controlled use of the medium: "I am very conscious about not letting people know everything about me. First, I had about 500-600 pictures of me, but now I have untagged many. I'm now down to 120 pictures" (JP). And when this respondent was asked further into this - the answer was: "I think I grew up." First, it was fun with the party pictures, but all of a sudden having pictures of you drunk on Facebook is not all that fun anymore - something that your boss, colleagues and family could see. Things that you thought were funny at that time are suddenly not that funny anymore. This is a continuous process. Now I close much of it down to look after my private life" (JP).

But even though the respondents do communicate certain irritation towards opaque procedures on Facebook's behalf, particularly regarding privacy policy and how to guard yourself with different privacy settings, they put the responsibility on themselves, rather than Facebook: "You need to be alert to what you are sharing and to whom" (LO). And when asked further into this, the responded simply replied: "I choose to share information that I feel comfortable sharing" (LO).

Finally, when asked about their political use of Facebook, the respondents were quite frank none of them use Facebook for political purposes. Indeed, people that generate political communication on Facebook irritate them: "There are many Danes that know nothing about politics and all of a sudden they use Facebook to send trivial political message. I do not have the patience to have political discussion on Facebook and I am not sure whether Facebook as a medium is suitable for it. If I am writing longer, more reflective texts, I usually use private messages" (LO). This goes hand in hand with the interviewees general use and motivation for being on Facebook - it is primary used to maintain friendships, for planning everyday activities, to network, and for all the amusing everyday activities that reside within the cultural public spheres - rather than the political one. Therefore, my respondents clearly act as weak publics regarding motivation and use - a point that 
is exemplified in the following remark: 'It is all the fun stuff and the practical stuff. I am not at all political on Facebook' (JU).

\subsection{Advertising and Ownership}

As illustrated in the previous section, the seven respondents were all aware of polemics regarding terms of sharing, the way that settings for sharing have traditionally been designed, and ownership and user terms of uploaded material. Even though all of them have been on Facebook for some years and mentioned this process of "taming" it, as an important manifestation of emancipation, none of them had fully read Facebook's privacy policy. When asked further into these polemics, many referred to the film The Social Network. The respondents fully realized that the film was a fiction, but the source of scepticism is all the same to be traced to the film, and in some cases to discussions in the media. What is interesting is the fact that all of my respondents trust Facebook, despite the ambiguities that they detect. The main reason for this trust is, however, not Facebook's privacy policy/data use policy or Facebook's statement of rights and responsibilities, as they did not read these. The reason is rather the fact that as Facebook is a private company that thrives on having engaged users operating within its network - it cannot let its users down, leak information or betray them in any way. In addition, it is hard for the respondents to imagine why Facebook would be interested in their uploaded material in the first place: "I think about in which contexts Facebook would want to use my private pictures and for what purpose. Furthermore, I have not had any negative experiences where Facebook has used my material. So I trust Facebook not to use it" (TA).

This level of trust is again detectable in the interviewees opinions regarding user terms and ownership of information, where all of them had heard (again, they did not read statement of rights and responsibilities) that when they actively contributed material to Facebook, they at the same time gave Facebook right to use that information: "I am fully aware that as soon as I upload my pictures on Facebook, the pictures are as much Facebook's property, as they are mine. But they cannot use the pictures without notifying me" (LO). While this particular user is informed, other respondents had a more relaxed view on the issue of ownership, stating that this was not a problem for them: "This does not really concern me. In a bigger perspective, I can see that this could be problematical, but I am just tired of talking about it. There is always someone saying that this could potentially be scary. But it is difficult not to be on Facebook, because of all the practical things. From an ethical point of view there is a lot of problems associated with this, but on a personal level, this is not significant" (SU). As can be seen, this particular user is aware of polemics regarding ownership of material, which users upload and post on Facebook. However, these concerns are secondary to the network and the practicalities of everyday life associated with Facebook. Other respondents were more sceptical, but again, evaluate that despite these ownership polemics, they still have agency when interacting with Facebook as a media environment:"l think this is really outrageous. In some way I feel that it is acceptable that I use their site and they make a lot of money. But the fact that they also get rights to use our material - I think that is awful. But this is just how it is. There has been a lot of discussion in the press about this and I think that most people know about this. Because of this I choose not to upload my best pictures" (JP).

Here again, there is a tendency to tailor Facebook towards their own need and agenda, rather than perceiving themselves being succumbed under Facebook's statement of rights and responsibilities. This is particularly obvious in the answers provided by respondents that work within production and design industries: "I am aware of the copyright issue and that's why I have deleted many albums and now I only upload pictures taken on the mobile phone. I want to upload my good pictures but I do not do it because of copyright" (JU).

Regarding the advertisements on Facebook, the respondents find it interesting that information on Facebook is tailored to target users as consumers. They do, however, not find it problematic, as they do not feel that the announcements affect them at all: "I really do not notice the advertisements. It really takes something interesting to catch my attention, but generally, all that is in the right side of the screen [where advertisements are placed on users' walls] is not important to me" (LO). The same goes for another respondent that answered similarly: "I think I ignore it. If I could choose whether the announcements were there or not - I would probably choose not to have them. But this does not irritate me at all" (GI). Furthermore, the respondents had difficulties in identifying with the kind of advertisements that Facebook makes visible on their profiles, pointing towards subjects like loosing weight, make-up, Viagra, "and generally girly things" (SU) that they did not relate to. However, this was rather a source of laughter, than irritation. Indeed, the respondents did either not notice the advertisements, or simply looked upon this as a good service in a society that targets us anyway as consumers: "I think it is really useful to get advertisements that I can actually use - that are targeted to me" (JP). 
Finally, none of the respondents expressed scepticism towards what has been termed in this article produsage/prosumer commodity. Indeed, the interviewees express respect for Facebook's business model, as "it is brilliantly made and in line with the current Zeitgeist" (GI). Others do not see it as a problem as it is a win-win situation: "I feel that I get a lot from it as well. In fact, I am really content with Facebook. I do not think so much about this - but feel that they did all the hard work and are now gaining from that" (JU). More comments confirm this statement where emphasis is put on the craft and the general idea behind Facebook. Furthermore, respondents again feel that they are not being exploited as they get something valuable in return: "I do not feel exploited. I am perfectly aware of the fact that Facebook is there to make money. But there are many free functions and a network that I can use, so I never felt that Facebook has utilized me. I do not mind if someone is making money from it. If I develop a good concept, I also want to earn money from it" (GI).

\subsection{Public vs. Private}

Once more, the interviewees perceive their use of Facebook being far more advantageous than disadvantageous. This is so when looked upon from the viewpoint of their own use of the platform, as well as on terms of use and consumerism. Indeed, comments akin to "I do not give much to Facebook - I receive more" (JU) were often heard. This is also the case when asked about the respondents' views on how Facebook treats and affects the concept the public and the private i.e. the interviewees articulate clearly that Facebook has changed their perceptions on what it means to be public and private. However, again, they feel that it is up to them to control the accessibility of their own profile, and all respondents have changed the privacy settings on their profiles: "I have done that a lots of times. It is because I do not want foreign people to see me and my niece read a book together, or whatever you are doing. I do not wish to be a totally public person" (TA).

Furthermore, all of the respondents are very articulated on their own perceptions regarding what kind of issues should remain private, and what should be public when they update their status': "I write about something that I am looking forward to. For instance if I am going to a concert. Not the private things. I would never write, for instance that my aunt died. I write about superficial things" (JP).

At the same time, the interviewees feel frustrated about repeated changes in privacy settings and some of them have a feeling they could protect themselves even more, but do not know how to do it because of the complexity in Facebook's settings. This frustration is again detected in their opinion of how Facebook communicates with its users when changes are made in settings or interface: "I try to read it but the language they use is difficult. I am sure it can be done simpler, but they do it consciously, both to ensure that it is precise, and to make sure people cannot see through their policies" (JP). This point is confirmed by another respondent who has this to say about why Facebook's privacy policy is communicated with such complexity: "I am convinced that they do not want us to read it because we are most certainly going to find things that we are not happy to discover. So, if we do not read it, then we ignore the privacy concerns that we otherwise might encounter" (LO). Others ignore it as they get irritated of the frequency and the level of constant adaptation that these changes inflict on them: "I do not bother to read all this and when Facebook asks me, I just press skip each time" (GI).

The respondents agree that the separation between the public and private has permanently changes because of Facebook, where everything becomes more public. This is interpreted by some as being negative: "As soon as you enter the world of Facebook and social media there is no way back. You can never erase or exonerate your name or your pictures, or the things you have said or done. And this will be abused" (BT). Others, that look negatively upon a shrinking private sphere mention personal experiences of almost being caught smoking by parents on a picture on Facebook, or express concerns about what lies out there when they finish university and start looking for a job. These voices were, however, very clear on that scenarios like that were not Facebook's fault, but rather their own.

Indeed, respondents generally look upon the information society as being open to streams of information. This grossly affects their "older" presumptions of what the private and the public realms constituted - but at the same time the respondents claim that this is something people agree upon being a part of, and therefore, they have to take the consequences: "It was me who said yes to being on Facebook and I will have to learn to control the medium. It is my responsibility" (JP). Another respondent phrased a similar concern with the following words: "Facebook is only one part of this. Information about me is scattered thousand different places, and this is a fact that I will have to accept. There are advantages and disadvantages" (SU). 


\section{Elements of Colonization - Elements of Emancipation}

The purpose of this article is to trace elements of colonization and emancipation in Facebook as a media environment. In order to do this, Facebook was framed as a digital public sphere and analyzed from a communicative-structural context and by collecting qualitative data from seven Danish Facebook users. The communicative-structural analysis focused on Facebook's user terms, user manoeuvre, privacy policy, and ownership and use of uploaded material - while the latter focused on the actual experience of the users. Not surprisingly, the conclusion points towards both elements of colonization and elements of emancipation. The reason for why I say not surprisingly is because this has always been the case with the notion of public sphere(s). All communicative spaces - or public spheres - have inherent settings that facilitate certain forms for communication - thereby excluding alternative ways of conducting communication.

This is certainly the case with Facebook, as it is designed to allow for different forms for communication - which in Habermas' optic are in most cases not suitable for what could be termed meaningful deliberation. Indeed, there is evidence in the communicative-structural analysis which point towards regressive experiences associated with the consumption of mass culture; and not the cumulative experiences of serious involvement. This can be traced in the way Facebook has tailored its interface, but more importantly, in the privacy/data use policy, in the statement of rights and responsibilities, and in the way users are targeted as consumers. This is also the case in the data extracted from the Danish users, who primarily used Facebook for practical organisation, networking - and for fun. Indeed, the words superficial and self-promotion were often heard associated with Facebook as some kind of an inferior "world": "I know people that have terminated their Facebook accounts stating that they are fed up with this self-promoting bullshit and want to go out in the real world instead" (LO).

This is confirmed in my respondents lack of political activity on Facebook, and what on the surface might be interpreted as a lack of rationality: "I think it is very seldom that I encounter anything serious on Facebook. In some cases I get links with propaganda. But mostly, it is about experiences, the emotional, private life, and people's feelings" (TA). This is interesting from the viewpoint of the rational-criticality that Habermas associates with political public spheres, as my interviewees do not prioritize this kind of communication. Indeed, when it occurs, it generates irritation, rather than deliberation - associated with spam, rather than serious involvement. However, this does not mean that rational-critical communication never finds place on Facebook. On the contrary, there are many examples of the opposite - even though my respondents did not prioritize this kind of use.

This is important, as indeed public spheres do not act - but different publics do. When this is converted into digital cultures, networked publics act on Facebook. And these different networked publics have different agendas for generating their streams of information. Habermas made this distinction as well with his episodic, occasional and abstract publics, which can have different agenda for their communication. This was clearly the case with the interviewees who all "tamed" Facebook as a public sphere in order to generate communication that do have elements of the counter potentials which Habermas saw essential to cultural reproduction, social integration and socialisation. These are every-day activities taking place in the cultural public spheres - where renting an apartment through Facebook, recruiting someone for work, getting a job, buying a sofa, constructing networks, organizing practicalities and all the fun stuff were specifically mentioned as empowering, emancipative acts. Furthermore, these every-day activities are capable of generating conditions of communication where discursive formation of opinion and will is expressed. In most cases, the networked publics engaging in this kind of communication are weak, since they do not affect the political public spheres. However, this really depends on the density of communication, organizational complexity and range. Indeed, Facebook is a post-bourgeois hybrid. Even though the communication taking place there usually facilitates weak publics (opinion formation), the intraand inter-relations of networked publics certainly have the potentials to generate communication streams where these publics are empowered into strong publics (opinion formation and decision making) - thereby not only influencing opinion making, but also decision making in the political spheres. It is through these means a communicative environment like Facebook acts as a public sphere that provides feedback between elite discourse and responsive civil society.

However, as preciously mentioned, users are strategically targeted as consumers on Facebook - making the distinction between emancipative cultural participation and the category of the produsage/prosumer commodity fuzzy to say the least. The question remains whether it is fit to maintain that Facebook represents a colonizing mediatisation of the lifeworld - when the users do not perceive it as such? - On the other hand, such concealed, devious colonization is usually the most powerful one, as people only realise its mechanism and its consequence when it is too late. 


\section{References}

Adorno, Theodor. 2001. Culture Industry Reconsidered. In The Culture Industry, edited by J.M. Bernstein, 98-106. London: Routledge.

Adorno, Theodor, and Max Horkheimer. 2002. Dialectic of Enlightenment: Philosophical Fragments. Stanford: Stanford University Press.

Arsenault, Amelia, and Manuel Castells. 2008. The Structure and Dynamics of Global Multi-Media Business Networks, International Journal of Communication 2: 707-748.

boyd, danah, and Eszter Hargittai. 2010. Facebook Privacy Settings: Who Cares? First Monday 15 (8). Accessed August 3 , 2011. http://firstmonday.org/htbin/cgiwrap/bin/ojs/index.php/fm/article/view/3086/2589

Bruns, Axel. 2008. Blogs, Wikipedia, Second Life, and Beyond: From Production to Produsage. New York: Peter Lang.

Calhoun, Craig. 1992. Introduction: Habermas and the Public Sphere. In Habermas and the Public Sphere, edited by Craig Calhoun, 1-48. Cambridge: MIT Press.

Carpentier, Nico. 2011. Media and Participation: A Site of Ideological-Democratic Struggle. Bristol: Intellect.

Castells, Manuel. 2000. The Rise of the Network Society. Oxford: Blackwell.

Castells, Manuel. 2004. Informationalism, Networks, and the Network Society. A Theoretical Blueprint. In The Network Society: A Cross-Cultural Perspective, edited by Manuel Castells, 3-51. Cheltenham: Edward Elgar Publishing Limited.

Castells, Manuel. 2009. Communication Power. Oxford: Oxford University Press.

Cresswell, John. W. 2009. Research Design: Qualitative, Quantitative, and Mixed Methods Approaches. London: Sage.

Curran, James. 2002. Media and Power. London: Routledge.

Dahlberg, Lincoln. 2007. The Internet, Deliberative Democracy, and Power: Radicalizing the Public Sphere. International Journal of Media and Cultural Politics 3(1), 47-64.

Dahlgren, Peter. 2009. Media and Political Engagement: Citizens, Communication, and Democracy. Cambridge: Cambridge University Press.

Danskernes brug af internettet 2011. 2011. Copenhagen: Foreningen af danske interaktive medier.

Facebook (n.d., a). Data Use Policy. Accessed October 29, 2011. https://www.facebook.com/full data use policy

Facebook (n.d., b). Facebook's Privacy Policy. Accessed July 13, 2011. https://www.facebook.com/policy.php

Facebook (n.d., c). Statement of Rights and Responsibilities. Accessed October 29, 2011. https://www.facebook.com/terms.php

Facebook (n.d., d). Statistics. Accessed November 15, 2011. https://www.facebook.com/press/info.php?statistics

Facebook, n.d., e. Updates to News Feed. Accessed October 29, 2011. https://www.facebook.com/help/?page=189712557768134

Fraser, Nancy. 1992. Rethinking the Public Sphere: A Contribution to the Critique of Actually Existing Democracy. In Habermas and the Public Sphere, edited by Craig Calhoun, 109-142. Cambridge: MIT Press.

Fraser, Nancy. 2007. Transnationalizing the Public Sphere: On the Legitimacy and Efficacy of Public Opinion in a PostWestphalian World. Theory, Culture \& Society 24 (7): 7-30.

Fuchs, Christian. 2010. Labour in Informational Capitalism and on the Internet. The Information Society 26 (3), 179-196.

Garnham, Nicholas. 1990. Capitalism and Communication: Global Culture and the Economics of Information. London: Sage.

Gaskell, George. 2000. Individual and Group Interviewing. In Qualitative Researching with Text, Image and Sound, edited by Martin W. Bauer and George D. Gaskell, 38-56). London: Sage.

Gripsrud, Jostein, and Hallvard Moe. 2010. Introduction. In The Digital Public Sphere, edited by Jostein Gripsrud and Hallvard Moe, 9-19. Gothenburg: NORDICOM.

Habermas, Jürgen. 1987. The Theory of Communicative Action: Volume 2: Lifeworld and System: A Critique of Functionalist Reason. Cambridge: Polity Press.

Habermas, Jürgen. 1989. The Structural Transformation of the Public Sphere: An Inquiry Into a Category of Bourgeois Society. Cambridge: Polity Press.

Habermas, Jürgen. 1992. Further Reflections on the Public Sphere. In Habermas and the Public Sphere, edited by Craig Calhoun, 421-461. Cambridge: MIT Press.

Habermas, Jürgen. 1996. Between Facts and Norms: Contributions to a Discourse Theory of Law and Democracy. Cambridge: Polity Press.

Habermas, Jürgen. 1999. 'A Short Reply'. Ratio Juris 12 (4): 445-453.

Habermas, Jürgen. 2006. Political Communication in Media Society: Does Democracy Still Enjoy an Epistemic Dimension? The Impact of Normative Theory on Empirical Research, Communication Theory 16 (4): 411-426.

Ito, Mizuko. 2008. Introduction. In Networked Publics, edited by Kazys Vernelis, 1-14. Cambridge: MIT Press

Keane, John. 2000. Structural Transformations of the Public Sphere. In Digital Democracy: Issues of Theory and Practice, edited by Kenneth L. Hacker and Jan van Dijk, 70-89. London: Sage.

Kellner, Douglas. 1990. Television and the Crisis of Democracy. Oxford: Westwiew Press.

Kvale, Steinar, and Svend Brinkmann. 2008. InterViews: Learning the Craft of Qualitative Research Interviewing. London: Sage.

McCheseney, Robert. W. 1999. Rich Media, Poor Democracy: Communication Politics in Dubious Times. New York: The New Press.

McGuigan, Jim. 2005. The Cultural Public Sphere, European Journal of Cultural Studies 8 (4): 427-443.

Microsoft ${ }^{\circledR}$ News Center (n.d.). Facebook and Microsoft Expand Strategic Alliance. Accessed November 18, 2011. http://www.microsoft.com/Presspass/press/2007/oct07/10-24FacebookPR.mspx

Mouffe, Chantal. 2000. The Democratic Paradox. London: Verso.

Mouffe, Chantal. 2005. On the Political. London: Routledge.

Negt, Oskar, and Alexander Kluge. 1993. Public Sphere and Experience: Toward an Analysis of the Bourgeois and Proletarian Public Sphere. Minneapolis: University of Minnesota Press.

Nyt fra Danmarks Statistik Nr. 403. 2011. Befolkningens brug af internet (tillæg 1).

Papacharissi, Zizi A. 2010. A Private Sphere: Democracy in a Digital Age. Cambridge: Polity Press. 
Schrøder, Kim Christian. 2000. Making Sense of Audience Discourses: Towards a Multidimensional Model of Mass Media Reception. European Journal of Cultural Studies 3 (2): 233-258.

Schrøder, Kim Christian, Kirsten Drotner, Steve Kline, and Catherine Murray. 2003. Researching Audiences. London: Arnold.

Splichal, Slavko. 2010. Eclipse of 'the Public': From the Public to (Transnational) Public Sphere: Conceptual Shifts in the Twentieth Century. In The Digital Public Sphere, edited by Jostein Gripsrud and Hallvard Moe, 23-40. Gothenburg: NORDICOM.

Toffler, Alvin. 1980. The Third Wave. New York: Bentam.

Valtysson, Bjarki. 2010. Access Culture: Web 2.0 and Cultural Participation. International Journal of Cultural Policy 16 (2): 200-214.

Winner, Langdon. 1996. Do Artifacts Have Politics? In Technology and Society: Building Our Sociotechnical Future, edited by Deborah G. Johnson and Jameson M. Wetmore, 209-226. Cambridge: MIT Press.

\section{About the Author}

Bjarki Valtysson

is an assistant professor at the IT University of Copenhagen, where he is a member of the DCMC group (Design, Culture, Mobility, Communication) and Center for Network Culture. He earned a Ph.D.- degree from the University of Roskilde, Institute for Communication, Business and Information Technologies. He also has a M.A. degree in Cultural Studies from the University of Copenhagen and B.A. degree in Comparative Literature and Icelandic Philology from the University of Iceland. Amongst his research interests are cultural-, media-, and communication policies, social media, social network sites, performance design, and digital culture and cultural institutions. He has recently published a book on Icelandic cultural policy. 